\title{
Obesity as a prognostic factor in breast cancer women
}

\begin{abstract}
Obesity has a negative impact on cancer prognostic. Obese patients tend to present at the diagnosis of breast cancer tumors with biological characteristics of greater aggressiveness and in the follow up reduction in disease-free survival and overall survival.

Objective: the objective of this study was to evaluate the role of obesity as a prognostic factor in a group of women with breast cancer.

Methods: this is a retrospective hospital based study. The dependent variable was the progression or death by breast cancer in a 5-year follow-up and the independent variable was obesity.

Results: the median progression free survival (PFS) and the overall survival (OS) were calculated using the Kaplan-Meier method and the Cox regression model. The total of 274 patients, $62 \%$ were overweight and obese. Obese patients presented a higher proportion of larger tumors at diagnosis, between 2.0 to $5.0 \mathrm{~cm}$, and more advanced staging (E III) $(p=0.007)$. 5-year PFS was $74,7 \%$ for non-obese and $78,7 \%$ for the obese $(p=0,796)$. 5-year OS was $77,4 \%$ for obese and $81,2 \%$ for non-obese women $(\mathrm{p}=0,854)$. The detrimental effect of obesity in survival analyses was greater for younger patients but, in multivariate analysis, obesity was not an independent factor for worse prognosis.
\end{abstract}

Conclusion: This study showed obese patients present more advanced staging at diagnosis. A long-term follow-up of these patients can detect differences in survival.
Research Article

Volume 8 Issue 2 - 2018

\author{
Eni Devay de Freitas,' Marco Antônio \\ Vasconcelos Rêgo ${ }^{2}$ \\ 'State University of Bahia, Brazil \\ ${ }^{2}$ Federal University of Bahia, Brazil
}

Correspondence: Eni Devay de Freitas, State University of Bahia, ORCID 0000-000 I-5 I42-909, Brazil, Tel +55(71)981954065, Email enifreitas@hotmail.com

Received: February 07, 2018| Published: March 06, 2018

Keywords: breast cancer, obesity, prognostic factor, survival

Abbreviations: WHO, world health organization; BMI, body mass index; EMR, electronic medical record

\section{Introduction}

Cancer is a public health problem, according to the World Health Organization (WHO), ${ }^{1}$ not only because of its high mortality burden, but also because of its increased incidence and prevalence, especially in sites like breast, in the last two decades. ${ }^{2,3}$ Breast cancer is the most prevalent cancer in women in the world and in $3 / 4$ of the countries. The higher prevalence of breast cancer reflects the increase in survival that has been observed not only in developed but also developing countries such as Brazil. ${ }^{2}$ Of the 32 million cancer survivors in the world in 2012, 17 million were women and 6.2 million had breast cancer. $^{5}$

In 2012, 5,4\% (345.000) of the new cases of cancer in women were attributed to high Body Mass Index (BMI). ${ }^{6}$ Obese women have a higher risk of developing breast cancer than non-obese women, being in pos-menopausal ${ }^{7,8}$ and premenopausal. ${ }^{9}$ Obesity, in addition to being a risk factor, is a worse prognostic factor for cancer. According to WHO, one third of all cancer deaths in the world today are associated to five main factors related to lifestyle and diet, among them overweight and obesity. ${ }^{10}$ Meta-analysis studies have shown that obesity in women increases the risk of death from breast cancer by almost two times..$^{11,12}$ Obese patients tend to present larger tumor size, positive lymph node status, more advanced staging at diagnosis and biological characteristics of greater aggressiveness due to the degree of tumor differentiation in relation to non-obese patients. ${ }^{13-15}$ This reflects in increased relapse rates and disease progression, reduction in disease-free survival, ${ }^{16}$ and overall survival due to breast cancer. ${ }^{17,18}$ On the other hand, weight loss is associated with a $53 \%$ reduction in cancer-related deaths and weight loss or weight maintenance in women from the ages of 18 to 30 years reduces the risk of postmenopausal breast cancer. ${ }^{19,20}$

Physical and emotional disabilities in surviving breast cancer patients impact negatively in quality of life, social insertion and in work. Detecting modifiable risk and prognostic factors such as obesity related to breast cancer is extremely relevant to possible improvements in this context. ${ }^{21}$ This study aims to evaluate the role of obesity in the survival of women diagnosed with breast cancer considering the presence of other prognostic factors related to the tumor.

\section{Methods}

This is a survival study of patients diagnosed with breast cancer and its relation with obesity and tumor prognostic factors. The study consisted of a hospital-based sample of women over 18 years of age, with diagnostic confirmation of breast cancer, attended at a private institution for cancer treatment in the city of Salvador, Bahia, Brazil, in the period 2009-2012. Patients were selected through a database search of the institution's electronic medical record (EMR). All female patients above 18 years of age who had diagnostic confirmation 
of breast cancer were eligible for inclusion. Patients were selected through coding for the disease according to ICD-10 (International Classification of Diseases, 10th edition, 1998) -c50- which includes the histology of invasive breast carcinoma. The data collected and the histological confirmation were obtained by consulting the medical record and accessing the pathology reports. Obesity, defined as the main independent variable, was classified according to the weight and height data of the patients contained in the EMR. The Body Mass Index (BMI) was calculated as weight $(\mathrm{kg}) /$ height $(\mathrm{m})$, and was divided into two variables: an obese $(\mathrm{BMI}=>30)$-non-obese $(\mathrm{BM}<30)$ dichotomy. Overweight was defined by BMI between 25.0 and 29.9); GI obesity- BMI between 30 and 34.9; GII obesity - BMI between 35 and 39.9) and GIII obesity-BMI $=>40$.

The patients were categorized by staging of the disease according to medical records according to the 7th edition of the TNM breast cancer. Tumor size was categorized by size in centimeters $(\mathrm{cm})$ : less than 1.0 $\mathrm{cm}, 1.0$ to $2.0 \mathrm{~cm}, 2.1$ to $5.0 \mathrm{~cm}$ and greater than $5,0 \mathrm{~cm}$. Axillary lymph node involvement was defined as positive or negative lymph node (in sentinel lymph node or axillary emptying), and the number of lymph were not considering. The Hormonal Receptor (HR) was categorized by the findings of immunohistochemistry as positive in cases of estrogen and / or progesterone receptor positive, and negative if both estrogen and progesterone receptors were negative. HER2 hyperexpression was defined as positive if immunohistochemistry was $3+$ or FISH positive; HER2 negative, if the immunohistochemistry was $1+, 2+$ or negative FISH. ${ }^{22}$ Based on the findings of the Hormonal Receptor and HER2 expression the patients were grouped by histological subtypes in: HR positive and HER2 negative (luminal A-like), HR and HER2 positive (luminal B-like), HR negative and HER2 positive (enriched by HER-2) and negative HR and negative HER2 (triple negative). ${ }^{23}$ For each individual, the date of diagnosis was considered as the moment of entry into the sample in the years 2009 to 2012. Their records were tracked until the date of collection in the period from $08 / 15 / 2015$ to $09 / 15 / 2015$.

The event of interest was the time between the diagnosis of the disease and the first event defined as: progression of disease or death. Disease progression was defined as the recurrence of cancer in patients stages I to III who were without evidence of disease and, for patients in stage IV, under treatment or follow-up, the progression of cancer in primary site and /or metastases. Patients who lost or did not present the endpoint/event of interest until the time of data analysis were censored and included in the survival analysis, as well as patients who died due to causes not related to breast cancer. ${ }^{24}$

\section{Statistical considerations}

Data analysis was performed in three stages. The frequencies, measures of central tendency and dispersion, and the association between obesity and the covariates were calculated using the Pearson chi-square test. The second step was the survival analysis using the Kaplan-Meyer method, obtaining the curves and rates of Progressive Free Survival (PFS) and Overall Survival (OS) for the whole sample and according to the independent variable obesity and the variables age, staging, tumor size, axillary lymph node, tumor grade, HR expression, HER2 status and histological subtype. The survival curves (PFS and OS) for each variable were compared using the log-rank test. In the last step Cox's multivariate regression analysis ${ }^{25}$ was performed to evaluate the role of obesity and variables as independent prognostic factors for breast cancer. The verification of compliance with the proportional hazards assumption for the variables was performed by comparing survival curves observed with those estimated by the Cox model. The level of significance for pre-selection of variables using the bivariate Cox regression was 5\%. All variables that met the proportional hazards assumption were pre-selected and the backward modeling method was stepwise; the statistical test for removal of variables was the maximum likelihood method, with significance level of 5\% and the method for entry of the variables was the test score, with the same level of significance. Statistical Package of Social Sciences "SPSS" was used to carry out these analyses.

The project was submitted to the Research Ethics Committee of the Bahia Medical School of the Federal University of Bahia on $07 / 07 / 2015$ and was approved for its execution on 08/04/2015 under the number CAAE 47385115.2.0000.5577.

\section{Results}

A total of 274 patients were included in the study. The patients' ages ranged from 25 to 90 years, with a median age of 58 years. Two-thirds of the patients were aged $>=50$ years, which corresponded to $69 \%$ of the menopausal women. 262 patients had weight $(\mathrm{kg})$ and height $(\mathrm{m})$ register for calculated BMI. Seventy-two patients (28\%) were obese and ninety patients (34\%) were overweight. Among obese patients, $72 \%$ had GI obesity, $22 \%$ GII obesity and $4 \%$ morbid obesity. $67,3 \%$ of the patients had tumors smaller than $2.0 \mathrm{~cm}: 22,7 \%$ of these tumors were smaller than $1.0 \mathrm{~cm}$ and $34,6 \%$ between 1.0 and $2.0 \mathrm{~cm}$. Negative lymph node occurred in $64,1 \%$ of the women. Staging distribution showed that most patients were diagnosed in the initial stages I, 40,4\% and II, 33,2\%. 18,5\% percent had stage III disease and 7,9\% were stage IV at diagnosis. The histological characterization of the tumors was $16,9 \%$ GI, $46,7 \%$ GII and $36,4 \%$ GIII. The hormonal receptor (HR) was positive in $77 \%$ of the women and HER-2 expression, positive in $17,1 \%$. The most frequent histological subtype was HER2 negative and HR positive with $66,9 \%$ of the tumors, followed by triple negative $(16,3 \%)$, HR positive and HER2 positive $(10,4 \%)$ and enriched by HER $2(6,3 \%)$. The proportion of consecutive patients who progressed was $20 \%(\mathrm{n}=55)$ and the proportion of patients who died was $16,8 \%(n=46)$.

There was no difference in the proportion between obese and nonobese patients in relation to the variables as age $(>=50$ years and $<50$ years), menopausal status, axillary lymph node involvement, staging and expression of HR, HER 2 and histological subtype. Obese patients had proportionally more higher proportion of larger tumors between 2 to $5 \mathrm{~cm}, 45,9 \%$ versus $39,6 \%$ for non-obeses, whereas non-obese patients had a higher proportion of tumors less than $1.0 \mathrm{~cm}, 25,7 \%(\mathrm{p}$ $=0.007)$. Obese patients were more likely to have advanced local disease, E III 27,4\%vs 15,9\% in non-obese, while non-obese patients had initial staging disease, EI in $42,6 \%$ vs. $32,9 \%$ for obese ( $p=0.007$ ) (Table 1). The proportion of breast cancer progression was similar for obese and non-obese patients: $22 \%$ and $19,6 \%$, respectively. The proportion of deaths due to breast cancer did not differ for obese patients, $17,5 \%$ compared to non-obese, $16 \%$.

The follow-up for progression had a median of 44 months +/20.3 months, a minimum of three months and a maximum of 79 months. For the death event, the median follow-up was 46 months +/- 19.4 months, minimum three months and maximum of 79 months. Estimated 1-year and 5-year overall survival (OS) was 96,6\% and $79,3 \%$, respectively. 1-year and 5-year of progression-free survival 
(PFS) was $93 \%$ and $77,5 \%$, respectively. OS rates were worse for nonobese women ( $89,4 \%$ versus $91,4 \%$ for obese) in the first two years, with curves crossing after the third year of follow-up, and 5-years OS was $77,4 \%$ in obese and $81,2 \%$ in non-obese (Figure 1). 2-year PFS did not differ between obese and non-obese women: $87,3 \%$ and $85,2 \%$, respectively. There was a non-significant 5 -year difference of $74,7 \%$ for obese and $78,7 \%$ for non-obese with trend of withdrawal from PFS curves (Figure 2). Survival analysis, according to the prognostic variables for breast cancer, obesity, menopausal status and HER2 expression did not differ in relation to PFS and OS. Tumors smaller than $1.0 \mathrm{~cm}$ had 5-year OS and PFS of 98,2\% compared to significantly lower survival rates for tumors over $5.0 \mathrm{~cm}$ in 2- and 5 -years, from $53,8 \%$ and $34,6 \%$ for OS and $53,8 \%$ and $38,5 \%$ for PFS, respectively. Patients with positive lymph node had worse survival than those with negative lymph node: 5 -years OS and PFS were $63,2 \%$ and $58,5 \%$,respectively in positive lymph node. 5-years OS was $95,4 \%$ in stages I, $87,4 \%$ in stages II, $40,9 \%$, III and $19,9 \%$ in IV; 5 -year PFS was $97,0 \%$ in stage I, $89,5 \%$ in II, $46,3 \%$ in III and $15,9 \%$ in IV (Table 2). 5-year OS was $98,9 \%$ for well differentiated patients and $71,2 \%$ for the poorly differentiated; 5 -year PFS was $99,6 \%$ for the well differentiated compared to $69,2 \%$ for the poorly differentiated ones. Patients HR negative had worse survival than those HR positive: 5 -year OS and PFS were $60,8 \%$ and $61,7 \%$, respectively. In relation to the histological subtypes, triple negative tumors presented the worst 5 -year OS and PFS 54,5\% and 53,8\%, respectively (Table 2).

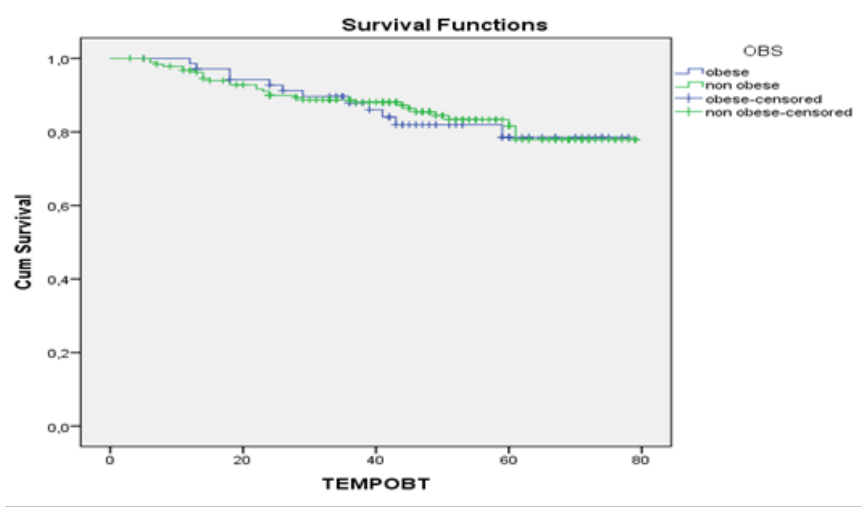

Figure I Kaplan-Meier estimates of overall survival by obesity at baseline for obese versus non-obese patients.

Table I Characteristics of patients by the prognostic variables of the tumor according to obesity

\begin{tabular}{|c|c|c|c|c|c|}
\hline \multirow[t]{2}{*}{ Variable } & \multicolumn{2}{|c|}{ Obese } & \multirow{2}{*}{$\begin{array}{l}\text { Non } \\
\text { N }\end{array}$} & \multirow{2}{*}{$\begin{array}{l}\text { Obese } \\
\%\end{array}$} & \multirow{2}{*}{$\begin{array}{c}P \\
\text { value }\end{array}$} \\
\hline & $\mathbf{N}$ & $\%$ & & & \\
\hline \multicolumn{6}{|l|}{ Age, Years } \\
\hline$<50$ & 23 & 31,1 & 68 & 36,2 & \\
\hline$>=50$ & 51 & 68,9 & 120 & 63,8 & 0.52 \\
\hline \multicolumn{6}{|l|}{ Menopause } \\
\hline Postmenopause & 35 & 66,0 & 99 & 68,3 & \\
\hline Premenopause & 18 & 34,0 & 46 & 31,7 & 1 \\
\hline \multicolumn{6}{|l|}{ Tumor size } \\
\hline$<1,0 \mathrm{~cm}$ & 12 & 16,2 & 46 & 25,7 & \\
\hline $1,0-2,0 \mathrm{~cm}$ & 25 & 33,8 & 70 & 39,1 & \\
\hline $2,1-5,0 \mathrm{~cm}$ & 34 & 45,9 & 53 & 29,6 & \\
\hline$>5,0 \mathrm{~cm}$ & 3 & 4,1 & 10 & 5,6 & 0,007 \\
\hline \multicolumn{6}{|l|}{ Axillary Lymph Nodes } \\
\hline Positive & 28 & 41.2 & 60 & 34,4 & \\
\hline Negative & 40 & 58,8 & 114 & 65,6 & 0,4 \\
\hline \multicolumn{6}{|l|}{ Stage } \\
\hline I & 24 & 32,9 & 78 & 42,6 & \\
\hline II & 26 & 35,6 & 61 & 33,3 & \\
\hline III & 20 & 27,4 & 29 & 15,9 & \\
\hline IV & 3 & 4,1 & 15 & 8,2 & 0,007 \\
\hline \multicolumn{6}{|l|}{ Histologic Grade } \\
\hline Grade I & 5 & 8,2 & 32 & 20,6 & \\
\hline Grade II & 32 & 52,5 & 67 & 43,2 & \\
\hline Grade III & 24 & 39,3 & 56 & 36,2 & 0,08 \\
\hline \multicolumn{6}{|l|}{ Hormonal Receptor (HR) } \\
\hline Positive & 56 & 75,7 & 141 & 76,2 & \\
\hline Negative & 18 & 24,3 & 44 & 23,8 & 1,0 \\
\hline \multicolumn{6}{|l|}{ HER2 } \\
\hline Positive & 17 & 37 & 57 & 26,9 & \\
\hline Negative & 29 & 63 & 155 & 73,1 & 0,23 \\
\hline \multicolumn{6}{|l|}{ Histologic Subtype } \\
\hline HR positive and HER 2 negative* & 47 & 63,5 & 122 & 66,3 & \\
\hline HR positive and HER 2 positive & 10 & 13,5 & 18 & 9,8 & \\
\hline HR negative and HER2 positive & 6 & 8,1 & 11 & 6,0 & \\
\hline HR negative e HER2 negative & 11 & 14,9 & 33 & 17,9 & 0,7 \\
\hline
\end{tabular}

*HR Hormonal Receptor 
Table 2 Two-year and five-year Overall Survival (OS) and Progression-Free Survival (PFS) according to variables prognostic of the tumor

\begin{tabular}{|c|c|c|c|c|c|c|}
\hline \multirow[t]{2}{*}{ Variables } & \multirow{2}{*}{$\begin{array}{l}\text { OS* } \\
\text { 2-years \% }\end{array}$} & \multicolumn{2}{|l|}{ OS } & \multirow{2}{*}{$\begin{array}{l}\text { PFS** } \\
\text { 2-years \% }\end{array}$} & \multicolumn{2}{|l|}{ PFS } \\
\hline & & 5-years \% & p value & & 5-years \% & p value \\
\hline \multicolumn{7}{|l|}{ Age, Years } \\
\hline$<50$ & 81,0 & 77,0 & & 86,0 & 67,8 & \\
\hline$>=50$ & 92,8 & 84,1 & 0,015 & 96,0 & 84,1 & 0,003 \\
\hline \multicolumn{7}{|l|}{ Obesity } \\
\hline Obese & 91,4 & 77,4 & & 87,3 & 74,7 & \\
\hline Non-Obese & 89,4 & 81,2 & 0,854 & 85,2 & 78,7 & 0,796 \\
\hline \multicolumn{7}{|l|}{ Menopause } \\
\hline Postmenopause & 89,8 & 80,9 & & 90,5 & 82,9 & \\
\hline Premenopause & 85,4 & 74,5 & 0,195 & 78,0 & 73,8 & 0,097 \\
\hline \multicolumn{7}{|l|}{ Size tumor } \\
\hline$<1,0 \mathrm{~cm}$ & 98,2 & 98,2 & & 98,3 & 99,3 & \\
\hline $1,0-2,0 \mathrm{~cm}$ & 95,0 & 85,0 & & 91,8 & 84,4 & \\
\hline $2,1-5,0 \mathrm{~cm}$ & 84,3 & 67,2 & & 78,9 & 66,2 & \\
\hline$>5,0 \mathrm{~cm}$ & 53,8 & 34,6 & 0,000 & 53,8 & 38,5 & 0,000 \\
\hline \multicolumn{7}{|l|}{ Axillary lymph nodes } \\
\hline Sim & 77,3 & 63,2 & & 68,7 & 58,5 & \\
\hline \multirow[t]{2}{*}{ Não } & 96,8 & 87,6 & 0,000 & 95,6 & 90,4 & \\
\hline & & & & & & 0,000 \\
\hline \multicolumn{7}{|l|}{ Staging } \\
\hline I & 99,0 & 95,4 & & 99,1 & 97,0 & \\
\hline II & 94,1 & 87,4 & & 92,0 & 89,5 & \\
\hline III & 75,8 & 40,9 & & 66,5 & 46,3 & \\
\hline IV & 60,1 & 19,9 & 0,000 & 45,9 & 14,9 & 0,000 \\
\hline \multicolumn{7}{|l|}{ Histologic grade } \\
\hline Grade I & 98,9 & 98,9 & & 99,6 & 99,6 & \\
\hline Grade II & 93,8 & 86,4 & & 88,9 & 86,8 & \\
\hline Grade III & 84,9 & 71,2 & 0,000 & 81,4 & 69,2 & 0,004 \\
\hline \multicolumn{7}{|l|}{ Hormonal Receptor (HR) } \\
\hline Positive & 95,0 & 85,0 & & 92,6 & 83,6 & \\
\hline Negative & 71,8 & 60,8 & 0,000 & 65,8 & 61,7 & 0,000 \\
\hline \multicolumn{7}{|l|}{ HER2 } \\
\hline Positive & 89,0 & 79,5 & & 86,6 & 80,7 & \\
\hline Negative & 90,1 & 79,9 & 0,96 & 86,5 & 78,1 & 0,732 \\
\hline \multicolumn{7}{|l|}{ Histological subtype } \\
\hline HR positive and HER2 negative* & 95,4 & 84,8 & & 92,0 & 83,3 & \\
\hline HRpositiveand HER2 positive & 89,0 & 83,4 & & 92,4 & 82,3 & \\
\hline HR negative and HER2 positive & 94,1 & 77,6 & & 88,2 & 82,4 & \\
\hline HR negative and HER2 negative & 63,6 & 54,5 & 0,000 & 60,4 & 53,8 & 0,000 \\
\hline
\end{tabular}


Differences were observed in the comparison of survival curves by the variable obesity and other covariables, represented by a marked reduction of OS and PFS for younger patients, age less than 50 years, and tumor size greater than $5.0 \mathrm{~cm}$ in obese patients. 5-year OS in younger women ranged from $33 \%$ in obese and $75 \%$ in non-obese, and PFS differed from $45 \%$ in obese to $74 \%$ in non-obese women.

In univariate analysis, all variables met the assumptions of "proportional hazards" except obesity, but because it was the main independent variable in the study, it was mandatory that it enter the model. All other variables met the assumption being included in the multivariate analysis for the progression and death events. The multivariate analysis showed that positive lymph node increased four times the risk of death; tumor size greater than $2.0 \mathrm{~cm}$, three times. Triple negative histological subtype increased 4.5 times the risk of death. For disease progression, patients being younger than 50 years increased the risk twice. Lymph node positive increased the risk five times, tumor size greater than $2.0 \mathrm{~cm}$-two a half times and
HR negative-three times, constituting independent factors of worse prognosis for progression (Table 3 ).

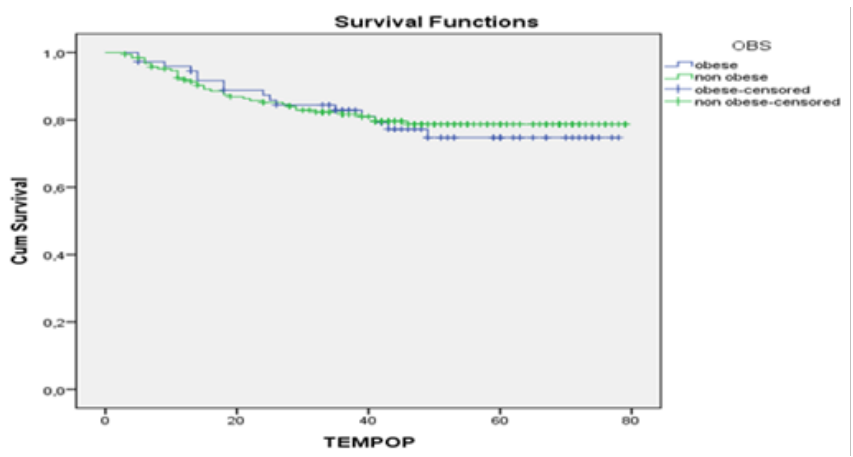

Figure 2 Kaplan-Meier estimates of progression free survival by obesity at baseline for obese versus non-obese patients.

Table 3 Multivariate analyses of COX for the variable obesity and covariates, according to progression and death

\begin{tabular}{|c|c|c|c|c|c|c|}
\hline \multirow[t]{2}{*}{ Variable } & \multicolumn{3}{|l|}{ PFS* } & \multicolumn{3}{|l|}{ OS $* *$} \\
\hline & $\mathrm{HR}^{* * *}$ & $95 \% \mathrm{CI}$ & p value & HR & $95 \% \mathrm{CI}$ & p value \\
\hline Age $<50$ years & 1.97 & $1.08-3.61$ & 0 & & & \\
\hline Axillarlymph node positive & 4.7 & $2.39-9.24$ & 0.027 & 4.53 & $2.15-9.56$ & 0 \\
\hline Size tumor $>2 \mathrm{~cm}$ & 2.64 & $1.39-5.02$ & 0.003 & 3.11 & $1.47-6.8$ & 0.003 \\
\hline Hormone Receptor Negative & 2.99 & $1.62-5.53$ & 0 & & & \\
\hline Triple negative Subtype & & & & 4.47 & $2.11-9.49$ & 0 \\
\hline
\end{tabular}

*PFS Progression-Free Survival

**OS Overall Survival

***HR Hazard Ratio; Cl Confidence Interval

\section{Discussion}

In this retrospective analysis, the results are comparable with data from international literature and population-based studies in Brazil regarding the median age at diagnosis and menopause as the most frequent status in women with breast cancer, ${ }^{26-30}$ biologic prognostic tumor like HR status, HER2 and histological subtypes. ${ }^{31-33}$ The current study demonstrated that patients in local advanced stages, III and IV, were $19 \%$ and $8 \%$ respectively, which was comparable to data from Brazilian studies. ${ }^{28-30}$

The present study demonstrated that $62 \%$ of the patients with breast cancer were overweight and $28 \%$ obese. This was higher than the proportion of the Brazilian population overweight in $2014(52.5 \%)^{34}$ and higher than the proportion of women diagnosed with breast cancer in European and American studies. In a cohort of 460 women with breast cancer in Geneva, Switzerland, 26\% were overweight and $19 \%$ were obese..$^{35}$ In a case series study in Baltimore, USA, with 996 patients, $49 \%$ of the patients were overweight and obese. ${ }^{14}$ The BIG 02-98 showed that $19 \%$ of the patients were obese. ${ }^{17}$ A Brazilian study by Sampaio et al. ${ }^{36}$ and a Mexican study by Arce-Salinas et al. ${ }^{37}$ presented data on the proportion of obesity and overweight of $70 \%$ and $74 \%$, respectively, in women with breast cancer, slightly larger but comparable to the current study.

Factors of worse prognosis for breast cancer such as tumor size (greater than $2 \mathrm{~cm}$ ) and more advanced staging (III and IV) at diagnosis had a statistically significant higher proportion in obese patients in compared to non-obese patients. Data from the international literature corroborate these findings: in Geneva, Switzerland, obese patients had a higher prevalence of nodal disease (54\%) and a higher proportion of disease in stages II to III. ${ }^{35}$ In the study by Cuy et al. ${ }^{14}$ overweight and obesity were associated with more advanced disease staging (stages II to IV). In a cohort of pre-menopausal patients in England, obese patients had significantly larger tumors $(>2.0 \mathrm{~cm})$, poorly differentiated tumors, axillary lymph nodes positive, and HER2 expression than those with normal weight. ${ }^{16}$ In the BIG 02-98 study, obese patients had more advanced disease staging with larger tumors ( 2.1 to 5 centimeters) and axillary lymph nodes positive in the diagnosis than non-obese patients. ${ }^{17}$ A European study in Turkey in pre-menopausal women, obese women had a significantly higher proportion of undifferentiated tumors, angiolymphatic infiltration, histologic subtypes enriched by HER2 and triple negative. ${ }^{38}$

The 5-year overall survival of $79 \%$ in this study was equivalent to the results of age-standardized population-based survival studies ${ }^{2}$ and hospital-based in Brazil. ${ }^{27-39}$ The population-based study demonstrated that age-standardized 5-year survival for breast cancer in 34 countries was around $80 \%$ and in Brazil in 2009 it was $87 \% .{ }^{2}$ Yet in populationbased studies such as that of Coleman et al. ${ }^{40}$ data from the city of Campinas, São Paulo, Brazil, showed a 5-year survival of only $40 \%$. There is a trend to improvement in breast cancer survival in different continents, but with variations in these rates by countries, and in different areas in the same country like Brazil, from the attribution of investment, allocation of resources and public health. ${ }^{3}$ 
Patients with HER2 positive and negative status had the same survival in this study. This is justified by the access to anti-HER2 cancer therapy for all these patients, which does not correspond to the reality for all breast cancer patients in Brazil: patients who only have access to the country's public health service (SUS), the anti-HER2 therapy has been available only for adjuvant treatment from 2013. To this day, it is still not available in metastatic diseases. This impact is reflected in worse survival and estimation of premature deaths in Brazil in patients with HER2 expression due to the lack of access to anti-HER2 therapies, as shown in the study by Debiase et al. ${ }^{41}$

In the present study, lymph node positive, tumor size greater than $2.0 \mathrm{~cm}$ and triple negative histologic subtype were independent factors of worse prognosis for death. Age under 50 years, positive lymph node, tumor size greater than $2.0 \mathrm{~cm}$ and negative Hormonal Receptor were independent factors of worse prognosis for progression, and these findings are in agreement with established knowledge. ${ }^{42}$ Obese patients younger than 50 years had worse survivals than nonobese patients. These data reproduce meta-analysis results, ${ }^{11,12}$ which evaluated the relationship between obesity and breast cancer, showing a worse survival rate in pre-menopausal obese patients, with a $75 \%$ higher risk of breast cancer deaths comparing with postmenopausal obese patients with $47 \% .^{11}$

Acriticism of the current study is the short follow-up time of the patients: median follow-up for progression and death was 44 and 46 months, respectively. In early breast cancer, which constitutes the largest representation of the current study, late recurrences and deaths occurring after 5 to 10 years $^{43}$ and a follow-up beyond 10 years is necessary. Ewertz and collaborators ${ }^{18}$ followed obese and non-obese patients with breast cancer and observed a significantly greater risk of distance recurrence and lower overall survival for obese patients from 10 years of follow-up.

Recognizing and intervening in modifiable factors such as obesity is of great relevance in improving prognosis of breast cancer, whether in the context of integral individual or collective care. The studies demonstrate the importance of weight control and healthy lifestyle habits through diet and regular physical activity, in reducing risk and improving the prognosis of the disease. ${ }^{19,20,44}$

\section{Acknowledgment}

None.

\section{Conflict of interest}

The authors declare that they have no conflict of interest.

\section{References}

1. World Health Organization. Global Status Report on non communicable disease; 2014.

2. Allemani C, Wein HK, Carrera H, et al. Global surveillance of cancer survival 1995-2009 analysis of individual data for 25676887 patients from 279 population-based registres in 67 countries (CONCORD 2). Lancet. 2015;385(9972):977-1010.

3. De Angelis R, Sant M, Coleman MP, et al. Cancer survival in Europe 1999-2007 by country and age: results of EUROCARE-5 a populationbased study. Lancet Oncol. 2014;4(15):23-34.

4. Bray F, Ren JS, Masuyer E, et al. Global estimates of cancer prevalence for 27 sites in the adult population in 2008. IJ Cancer. 2012;132(5):1133-1145.

5. International Agency for Research on Cancer. GLOBOCAN: Estimates Cancer Incidence, Mortality and Prevalence Worldwide in 2012.

6. Melina A, Pandeya N, Bymes G, et al. Global burden of cancer attributable to high body-mass index in 2012: a population-based study. Lancet Oncol. 2015;16(1):36-46.

7. Eliassen AH, Colditz GA, Rosner B, et al. Adult weight chance on risk of posmenopause breast cancer. J American Med Assoc. 2006;296(2):193-201.

8. Renehan AG, Tyson M, Egger M, et al. Body-mass index and incidence of cancer: a systematic review and meta-analysis of prospective observational studies. Lancet. 2006;371(19612):569-578.

9. Emaus MJ, Van Gils CH, Bakker MF, et al. Weight chance in middle adulthood and breast cancer risk in the EPIC_PANACEA study. Int $J$ Cancer. 2014;135(12):2887-2899.

10. Cancer Research Fund International. Cancer Prevention \& survival Summary of global evidences on diet, weight, physical activity\& what increase or decrease your risk of cancer; 2015.

11. Chan DMS, Vieira AR, Auned D, et al. Body mass index and survival in women with breast cancer- systematic literature review and metaanalysis of 82 follow-up studies. Ann Oncol. 2014;25(10):1901-1914.

12. Protani M, Corry M, Martins JH. Effect of obesity on survival of women with breast cancer: systematic review and meta-analysis. $\mathrm{Br}$ Cancer Res Treat. 2010;123(3):627-635.

13. Baerclaz G, Li S, Prince KN, et al. Body mass index as a prognostic features in operable breast cancer: the International Breast Cancer Study group experience. Ann Oncol. 2004;15(6):875-884.

14. Cui Y, Whiteman MK, Flaws JA, et al. Body mass and stage of breast cancer at diagnosis. Int J Cancer. 2002;98(2):279-283.

15. Pajares B, Póllan M, Martin M, et al. Obesity and survival in operable breast cancer patients treated with adjuvant anthracyclines and taxanes according to pathological subtypes: a pooled analysis. Br Cancer Res. 2013;15(6):1-14.

16. Copson ER, Cutress RI, Maishmanan T, et al. Obesity and the outcomes of Young breast cancer patients in the UK: The POSH study. Ann Oncol. 2015;26(1):101-112.

17. Azambuja E, McCreskill-Stevens W, Francis P, et al. The effect of body mass index on overall and disease-free survival in node positive breast cancer treat with docetaxel and doxorrubicin contain adjuvant chemotherapy: the experience of the BIG02-98 trial. $\mathrm{Br}$ Cancer ResTreat. 2010;119(1):145-153.

18. Ewertz M, Jensen MB, Gunnarsdottir KA, et al. Effect of obesity on prognosis after early-stage breast cancer. J Clin Oncol. 2011;29(1):2531.

19. Harvie M, Howell A, Vierkant RA, et al. Association of gain or loss of weight before and after menopause with risk of post menopause breast cancer in the IOWA woman's health study. Cancer Epidemiol Biom Prev. 2005;14(3):656-661.

20. Drazin B, Epsteim S, Turner H E, et al. Obesity American Handbook of Endocrynology and Diabetes. New York: Oxford University Press, 2011:522-533.

21. Kilbourn KM, Borgai N, Durning PE, et al. Validaty of the Psycho-Oncology Screening Tool (POST). J Psychosocial Oncol. 2011;29(5):475-498. 
22. Fitzgibbons PL, Dillon DA, Alsabeh R, et al. Template for Reporting Results of Biomarker Testing of Specimens From Patients With Carcinoma of the Breast, 2014. Arch Pathol Lab Med. 2014;138(5):595601 .

23. The Cancer Genome Atlas Network. Comprehensive molecular portraits of human breast tumours. Nature. 2012;490:61-70.

24. Kleibaum D, Klein M. Survival analysis: a self-learning text. Springer; 1997.

25. Hosmer DW, Lemeshow S. Applied Logistic Regression. A WileyInterscience Publication, 2nd ed. Nova Iorque; 2004.

26. Abreu E, Koifman RJ, Fanqueiro AG, et al. Sobrevida de dez anos de câncer de mama feminino em coorte populacional em Goiânia (GO) Brasil, 1988-1990. Cad Saude Col. 2012;20(3):305-313.

27. Mendonça GAS, Silva AM, Caula WM. Características tumorais e sobrevida de cinco anos em pacientes com câncer de mama admitidas no Instituto Nacional do Câncer, Rio de Janeiro, Brasil. Cad Saude Pub. 2004;20(5):1232-1239.

28. Moraes AB, Zanini RR, Turchiello MS, et al. Estudos de sobrevida de pacientes com câncer de mama atendidos no Hospital da Universidade Federal de Santa Maria, Rio Grande do Sul, Brasil. Cad Saude Pub. 2006;22(10):2219-2228.

29. Nunes RD, Martins E, Freitas-Junior R, et al. Estudo descritivo dos casos de câncer de mama em Goiânia, entre 1989 e 2003. Rev Col Bras Cirurgia. 2011;38(4):212-216.

30. Instituto Nacional do Câncer (INCA). Informações de registros hospitalares de câncer como uma estratégia de transformação. Perfil do Instituto Nacional do Câncer José Alencar Gomes da Silva 25 anos. Ministério da Saúde, Instituto Nacional do Câncer, Rio de Janeiro; 2012.

31. Anderson WF, Rosenberg PS, Prat A, et al. How many etiologica subtypes of breast cancer: two, three, four, or more. J Natl Cancer Inst. 2014;106.

32. Blows FM, Driver KE, Schmidt MK, et al. Subtyping of breast cance by immunohistochemistry to investigate a relationship between subtype and short and long term survival: a collaborative analysis of data for 10,159 cases from 12 studies. PLoS Med. 2010;7(5):e1000279.

33. Lobbezoo DJA, Kampen RJW, Voogd AC, et al. Prognosis of metastatic breast cancer subtypes: the hormone receptor/HER-2-positive subtype is associated with the most favorable outcome. Br Cancer Res Treat. 2013;141(3):507-514.

34. VIGITEL Brasil. Vigilância de fatores de risco e proteção para doenças crônica por inquérito telefônico. Ministério da Saúde; 2014.

35. Deglise $\mathrm{C}$, Ouchardy $\mathrm{C}$, Usel $\mathrm{M}$, et al. Impact of obesity on diagnosis and treatment of breast cancer. Br Cancer Res Treat. 2010;20(1):185193.

36. Sampaio HAC, Oliveira NM, Sabry MOD, et al. Influência do Tipo de terapia Antineoplásica sobre Marcadores Antropométricos e Dietéticos em mulheres Portadoras de Câncer de Mama. Rev Brasileira Cancerologia. 2012;58(2):223-230.

37. Arce-Saline C, Aguillar-Pance JL, Villareal-Garza C, et al. Overweight and Obesity as poor prognostic factor in locally advance breast cancer patients. Br Cancer Res Treat. 2014;146(1):183-188.

38. Turkoz FP, Solak M, Petekkaya I, et al. The prognostic impact of obesity on molecular subtypes of breast cancer in premenopausal women. $J$ BUON. 2013;18(2):335-341.

39. Guerra MR, Mendonça GAS, Teixeira MTB, et al. Sobrevida de cinco anos e fatores prognósticos em coorte de pacientes com câncer de mama assistidos em Juíz de Fora, Minas Gerais, Brasil. Cad Saude Pub. 2009;25(11):2455-2466.

40. Coleman MP, Quaresma M, Berrino F, et al. Cancer Survival in five continents: a worldwide population-based study (CONCORD). Lancet Oncol. 2008;9(8):730-756.

41. Debiase M, Reinert T, Kaliks R, et al. Estimation of premature deaths from lack acess to anti-HER2 therapy for advanced breast cancer in the Brazilian public health system. J Global Oncol. 2016; 3(3):201-207.

42. Goldhirsch A, Glick JH, Gelber RD, et al. Meeting highlights: International expert consensus on the primary therapy of early breast cancer 2005. Ann Oncol. 2005;16(10):1569-1583.

43. Fisher B, Dignam J, Wolmark N, et al. Tamoxifen and chemoteraphy for lymph node-negative, estrogen receptor-positive breast cancer. $J$ Natl Cancer Inst. 1997;89(22):1673-1682.

44. Van Gemert WAM, Schuit AJ, Van Der Palen J, et al. Effect weight loss with or without exercise, on body composition and sex hormones in postmenopausal women: the SHAPE-2 trial. $\mathrm{Br}$ Cancer Res. 2015;17:120-132. 